\title{
The effects of BAFF and APRIL signaling on non-small cell lung cancer cell proliferation and invasiveness
}

\author{
MARTYNA WARAKOMSKA ${ }^{1 *}$, MARLENA TYNECKA $^{1 *}$, DOROTA LEMANCEWICZ ${ }^{2,3}$, KAMIL GRUBCZAK $^{1}$, \\ JANUSZ DZIECIOL $^{2}$, MARCIN MONIUSZKO ${ }^{1,4}$, ANDRZEJ ELJASZEWICZ ${ }^{1}$ and LUKASZ BOLKUN ${ }^{2}$ \\ ${ }^{1}$ Department of Regenerative Medicine and Immune Regulation, Medical University of Bialystok, 15-269 Bialystok; \\ ${ }^{2}$ Department of Human Anatomy, Medical University of Bialystok, 15-230 Bialystok; \\ Departments of ${ }^{3}$ Haematology and ${ }^{4}$ Allergology and Internal Medicine, \\ Medical University of Bialystok, 15-276 Bialystok, Poland
}

Received November 4, 2020; Accepted June 18, 2021

DOI: $10.3892 / \mathrm{ol} .2021 .12989$

\begin{abstract}
Lung cancer represents the most common type of human malignancy and is the main cause of cancer-associated mortality worldwide. To improve the effectiveness of treatment strategies, a better understanding of the mechanisms of cancer progression and invasiveness is required. Recently, B-cell activating factor (BAFF) and a proliferation-inducing ligand (APRIL), two relatively newly described cytokines belonging to the tumor necrosis factor superfamily, have been shown to play a role in cancer progression. However, at present, the effects of both cytokines on lung cancer cells remain unclear. The present study aimed therefore to understand the direct effects of BAFF and APRIL on non-small cell lung cancer (NSCLC) progression. To do so, reverse transcription quantitative PCR and western blotting were used to evaluate whether A549 and H2030 NSCLC cells express receptors for both BAFF and APRIL. The results demonstrated that both investigated cell lines expressed BAFF-R (receptor specific to BAFF only) and transmembrane activator and CAML interactor (TACI; shared receptor for both cytokines). In addition, functional experiments were performed to determine the effects of BAFF and APRIL stimulation on cancer cell
\end{abstract}

Correspondence to: Dr Lukasz Bolkun, Department of Human Anatomy, Medical University of Bialystok, ul. M. Sklodowskiej-Curie 24a, 15-230 Bialystok, Poland E-mail: Lukasz.Bolkun@umb.edu.pl

Dr Andrzej Eljaszewicz, Department of Regenerative Medicine and Immune Regulation, Medical University of Bialystok, ul. Waszyngtona 13, 15-269 Bialystok, Poland

E-mail: Andrzej.Eljaszewicz@umb.edu.pl

*Contributed equally

Key words: lung cancer, B-cell activating factor, a proliferationinducing ligand, B-cell maturation antigen, transmembrane activator and CAML interactor, B-cell activating factor receptor, tumor progression viability. The results demonstrated no direct effects of BAFF and APRIL on NSCLC cell proliferation and invasiveness. In summary, the present study demonstrated that NSCLC cells possess the ability to respond directly to both BAFF and APRIL. However, activation of BAFF-R and TACI signaling in cancer cells did not increase the proliferative capacity and invasiveness. Further investigation is thus required to better understand the role of BAFF and APRIL on the progression of NSCLC.

\section{Introduction}

Lung cancer is the most common malignancy diagnosed worldwide and represents the leading cause of cancer associated-mortality. Among all types of lung cancer, non-small cell lung cancer (NSCLC) is the most frequent, accounting for $\sim 85 \%$ of all lung cancer cases (1). Although lung neoplasm pathogenesis is known to rise constitutively, it is crucial to better understand the mechanisms of cancer progression, including mutual interactions between malignant and immune cells $(2,3)$. Due to immune regulatory properties, cancer cells regulate innate and adaptive immune responses, abolishing antitumor activities and supporting mechanisms promoting tumor progression $(4,5)$. Among tumor-infiltrating immune cells, the vast majority is represented by myeloid cells, such as monocytes/macrophages, which are referred to as tumor-associated macrophages $(6,7)$. Due to pleiotropic biological activities, myeloid cells play a central role in the regulation of the tumor microenvironment by means of secreted soluble factors, including proteins belonging to the tumor necrosis factor (TNF) superfamily $(8,9)$.

B-cell activating factor (BAFF) and a proliferation-inducing ligand (APRIL) are relatively newly discovered TNF superfamily members. Both ligands might act through direct interaction with shared receptors, such as B-cell maturation antigen (BCMA) and transmembrane activator and CML interactor (TACI), while BAFF is also explicitly recognized by $\mathrm{BAFF}$ receptor (BAFF-R). Both ligands serve a crucial role in $\mathrm{B}$ cell development, maturation and immunoglobulin class switching (10). Furthermore, BAFF was shown to stimulate anti-apoptotic signaling in tumor cells $(8,11)$. Previous 
studies demonstrated that BAFF could play a role in neoplasm progression and aggressiveness (12-14). In addition, it was reported that both BAFF and APRIL signaling might increase tumor cell proliferation and enhance tumor cell viability in response to chemotherapeutic drugs in hematopoietic malignancies $(8,9,15)$.

At present, to the best of our knowledge, the role of BAFF and APRIL in solid tumors development and progression remains unknown. However, the expression of their receptors was mainly reported in tumor-infiltrating cells $(16,17)$. Interestingly, elevated blood levels of BAFF and APRIL are associated with a higher stage of the disease and cancer invasiveness, such as in breast cancer, chronic lymphocytic leukemia and pancreatic cancer $(12,18)$. Furthermore, the elevated expression of BAFF and APRIL is associated with increased cell migration, epithelial-mesenchymal transistion and stemness, subsequently contributing to an aggressive phenotype of breast cancer $(12,19,20)$. Similarly, APRIL overexpression was shown to be associated with tumor progression and was therefore proposed as a potential prognostic factor in rectal cancer, pancreatic adenocarcinoma and various B-cell malignances (13). In addition, in hepatocellular carcinoma cells, APRIL can play pleiotropic biological activities. Subsequently, APRIL may support tumor growth or reduce cell proliferation, depending on the particular pathway activation (21). Previous studies reported for the first time the importance of BAFF and APRIL signaling in NSCLC $(22,23)$. However, to date, it remains unclear whether BAFF and APRIL may serve a direct role in regulating lung cancer cell proliferation and invasiveness $(22,24)$. The present study aimed therefore to evaluate the effects of BAFF and APRIL on NSCLC cell proliferation and invasiveness.

\section{Materials and methods}

Cell lines. The human NSCLC cell lines A549 and H2030 were purchased from the American Type Culture Collection. Cells were cultured in Dulbecco's modified Eagle's medium (PAN Biotech UK, Ltd.) supplemented with $10 \%$ of heat-inactivated and filtered FBS (PAN Biotech UK, Ltd.) and gentamycin (50 $\mu \mathrm{g} / \mathrm{ml}$; Gibco; Thermo Fisher Scientific, Inc.) and placed at $37^{\circ} \mathrm{C}$ in a humidified incubator containing $5 \% \mathrm{CO}_{2}$. Cells were passaged when at $70-80 \%$ confluence. Cells from the second to fifth passage were used for all experiments.

Reverse transcription quantitative PCR. To assess the expression level of BAFF, APRIL, BAFF-R, BCMA and TACI, cells were harvested, washed with PBS and lysed in RLT buffer (Qiagen) supplemented with 1\% $\beta$-mercaptoethanol (Sigma-Aldrich; Merck KGaA) at room temperature. Total RNA was extracted using the RNeasy Mini Kit (Qiagen) according to the manufacturers' protocol and quantified using NanoDrop (NanoDrop 2000c/2000; Thermo Fisher Scientific, Inc.). Reverse transcription was performed using the High-Capacity cDNA Reverse Transcription Kit (Thermo Fisher Scientific, Inc.) according to manufacturers' instructions. Commercially available TaqMan assays (Thermo Fisher Scientific, Inc.; Table I) and TaqMan Universal PCR Master Mix (Thermo Fisher Scientific, Inc.) were used according to manufacturers' instructions. The thermocyclig conditions were as follows: Polymerase activation at $95^{\circ} \mathrm{C}$ for $10 \mathrm{~min}$ followed by 40 cycles of denaturation at $95^{\circ} \mathrm{C}$ for $15 \mathrm{sec}$ and annealing/extension at $60^{\circ} \mathrm{C}$ for $1 \mathrm{~min}$. Samples were analyzed in the StepOne Plus system (Thermo Fisher Scientific, Inc.). Data were analyzed using StepOne Software v2.3 (Thermo Fisher Scientific, Inc.). The relative expression levels were normalized to endogenous control and were expressed as $2^{-\Delta \Delta \mathrm{Cq}}(25)$.

Western blotting. To evaluate the protein expression of BAFF, APRIL, BAFF-R, BCMA and TACI, cells were harvested, washed in PBS and lysed in RIPA buffer (Thermo Fisher Scientific, Inc.) supplemented with complete protease inhibitor cocktail (Roche Diagnostics) for $15 \mathrm{~min}$ on ice. The cell debris were removed by centrifugation at $13,000 \mathrm{x}$ g for $5 \mathrm{~min}$ at $4^{\circ} \mathrm{C}$. The concentration of total protein was assessed using Pierce ${ }^{\mathrm{TM}}$ BCA Protein Assay Kit (Thermo Fisher Scientific, Inc.) according to manufacturers' instructions. Proteins $(20 \mu \mathrm{g})$ were mixed with Lammli sample buffer (1:4; Bio-Rad Laboratories, Inc.) and heated at $95^{\circ} \mathrm{C}$ for 5 min. Proteins were separated on $4-10 \%$ TGX gel (Bio-Rad Laboratories, Inc.) and transferred onto nitrocellulose membranes (Bio-Rad Laboratories, Inc.) using the TransBlot turbo system (Bio-Rad Laboratories, Inc.). The membranes were blocked using 5\% skimmed milk dissolved in PBS and supplemented with $0.1 \%$ Tween-20 (Sigma-Aldrich; Merck $\mathrm{KGaA}$; T-PBS) for $1 \mathrm{~h}$ at room temperature. Membranes were incubated with primary antibodies overnight at $4^{\circ} \mathrm{C}$ (Table II). Subsequently, membranes were washed using 10X PBS (Corining) supplemented with $0,1 \%$ Tween-20 and incubated with specific HRP-conjugated secondary antibodies (Table II) for $1 \mathrm{~h}$ in room temperature. Bands were detected using the SuperSignal West Femto chemiluminescence substrate kit (Thermo Fisher Scientific, Inc.) and visualized with ChemiDoc Touch System (Bio-Rad Laboratories, Inc.). Relative expression levels were normalized to endogenous control ( $\beta$-actin) using ImageJ software v1.53 (National Institutes of Health).

Ligand receptor interaction blocking. To block the interactions of BAFF, APRIL and their receptors in A549 and H2030 cell lines, blocking antibodies for TACI (monoclonal mouse IgG1 clone \#165609; R\&D Systems, Inc.; cat. no. MAB174) and BAFF-R (monoclonal mouse IgG2a, kappa clone \#8A7; Thermo Fisher Scientific, Inc.) were used separately or in combination at $10 \mu \mathrm{g} / \mathrm{ml}$ for $24 \mathrm{~h}$ in standard cell culture conditions $\left(37^{\circ} \mathrm{C}, 5 \% \mathrm{CO}_{2}\right)$.

Cell proliferation assay. To assess the effects of BAFF and APRIL on lung cancer cell proliferation, the cells were harvested and labeled with carboxyfluorescein succinimidyl ester (CFSE; Sigma-Aldrich; Merck KGaA). The cells were cultured for $72 \mathrm{~h}$ in 24 well plates $\left(37^{\circ} \mathrm{C}, 5 \% \mathrm{CO}_{2}\right)$ in the presence of recombinant human BAFF or APRIL proteins at the concentrations of 50,100 or $150 \mathrm{ng} / \mathrm{ml}$ or without any stimulation (vehicle). The cells were acquired by using TrypLE Select (Thermo Fisher Scientific, Inc.) at 24, 48 and $72 \mathrm{~h}$. Subsequently, cells were washed in PBS and stained with 7-AAD as suggested by the manufacturer $(0,25 \mu \mathrm{g}$ per $1 \times 10^{6}$ cells; Becton-Dickinson and Company), and incubated 
Table I. TaqMan assays used for reverse transcription quantitative PCR.

\begin{tabular}{llll}
\hline Assay & Target species & Catalogue number & Manufacturer \\
\hline TNFSF13 (BAFF) & Human & Hs00198106_m1 & Thermo Fisher Scientific, Inc. \\
TNFSF13 (APRIL) & Human & Hs00601664_g1 & Thermo Fisher Scientific, Inc. \\
TNFRSF1 (BAFF-R) & Human & Hs00606874_g1 & Thermo Fisher Scientific, Inc. \\
TNFRSF1 (TACI) & Human & Hs00963364_m1 & Thermo Fisher Scientific, Inc. \\
TNFRSF1 (BCMA) & Human & Hs03045080_m1 & Thermo Fisher Scientific, Inc. \\
GADPH & Human & Hs02786624_g1 & Thermo Fisher Scientific, Inc.
\end{tabular}

APRIL, a proliferation-inducing ligand; BAFF, B-cell activating factor; BAFF-R, BAFF receptor; TACI, transmembrane activator and CAML interactor; BCMA, B-cell maturation antigen.

Table II. Description of antibodies used for western blotting.

\begin{tabular}{|c|c|c|c|c|c|c|c|}
\hline Antibody & Target species & Host & Isotype & Clone & Dilution & $\begin{array}{l}\text { Catalogue } \\
\text { number }\end{array}$ & Manufacturer \\
\hline BAFF-R & $\begin{array}{c}\text { Human, mouse } \\
\text { and rat }\end{array}$ & Mouse & $\operatorname{IgG} 2 b$ & H-1 & $1: 150$ & sc-365410 & $\begin{array}{c}\text { Santa Cruz } \\
\text { Biotechnology, Inc. }\end{array}$ \\
\hline TACI & $\begin{array}{c}\text { Human, mouse } \\
\text { and rat }\end{array}$ & Mouse & $\operatorname{IgG} 2 b$ & C-9 & $1: 200$ & sc-365253 & $\begin{array}{c}\text { Santa Cruz } \\
\text { Biotechnology, Inc. }\end{array}$ \\
\hline BCMA & Human & Rat & $\operatorname{IgG} 2 \mathrm{a}$ & 335004 & $1: 100$ & MAB193 & R\&D Systems, Inc. \\
\hline $\begin{array}{l}\beta \text {-actin } \\
(\text { Direct-Blot HRP) }\end{array}$ & $\begin{array}{c}\text { Human, mouse } \\
\text { and rat }\end{array}$ & Mouse & $\operatorname{IgG} 2 b$ & $2 \mathrm{~F} 1-1$ & $1: 1000$ & 643807 & BioLegend, Inc. \\
\hline $\begin{array}{l}\text { Anti-mouse IgG } \\
\text { HRP-conjugated }\end{array}$ & Mouse & Goat & $\mathrm{IgG}$ & Polyclonal & $1: 1000$ & HAF007 & R\&D Systems, Inc. \\
\hline $\begin{array}{l}\text { Anti-rat IgG } \\
\text { HRP-conjugated }\end{array}$ & Rat & Goat & $\operatorname{IgG}$ & Polyclonal & $1: 1000$ & HAF005 & R\&D Systems, Inc. \\
\hline
\end{tabular}

BAFF-R, B-cell activating factor receptor; TACI, transmembrane activator and CAML interactor; BCMA, B-cell maturation antigen. HRP, horseradish peroxidase; Ig, immunoglobulin.

for $15 \mathrm{~min}$ at $4^{\circ} \mathrm{C}$. Cells were analyzed on FACSCalibur flow cytometry system (Becton-Dickinson and Company). Data were analyzed using FlowJo software version 10.6.1 (Tree Star, Inc.). To set the gates for the analysis of proliferation (negative control), colcemid $(50 \mathrm{ng} / \mathrm{ml})$ was used to arrest the mitosis in metastatasis stage. Cell viability was assessed according to 7-AAD staining and viable cells were considered as 7-AAD negative.

Invasion assay. To evaluate the influence of BAFF and APRIL on non-small cell lung cancer invasiveness, a commercially available invasion assay (Cell Biolabs, Inc.) was used according to the manufacturers' instruction. Briefly, the membrane was rehydrated, and cell culture media containing $10 \%$ FBS (vehicle) or $10 \%$ FBS with BAFF $(150 \mathrm{ng} / \mathrm{ml})$ or $10 \%$ FBS with APRIL $(150 \mathrm{ng} / \mathrm{ml})$ was added to the lower well of the invasion plate. Subsequently, cells in single-cell suspension were placed in the insert. After $48 \mathrm{~h}$ incubation at $37^{\circ} \mathrm{C}$, the invasive cells were stained with cell stain solution, lysed with extraction solution and the absorbance was measured at
$560 \mathrm{~nm}$ using a plate reader (Ledetect; Labexim Products). The data were analyzed using MicroWin2000 software (OEM version; Labexim Products).

Statistical analysis. Statistical analysis was performed using GraphPad Prism 6 software (GraphPad Software, Inc.). Data were compared using Mann-Whitney U test or Kruskal-Wallis followed by Dunn's post hoc test. $\mathrm{P}<0.05$ was considered to indicate a statistically significant difference. The results from at least five independent experiments are presented as the median \pm interquartile range.

\section{Results}

NSCLC cells express BAFF, APRIL and their receptors. First, we aimed to investigate whether NSCLC cells could express BAFF, APRIL and their receptors BCMA, TACI and BAFF-R using RT-qPCR and western blotting (Fig. 1). The results demonstrated that A549 and $\mathrm{H} 2030$ cell lines expressed BAFF, APRIL and BAFF-R (Fig. 1A-C). Conversely, the expression 
A
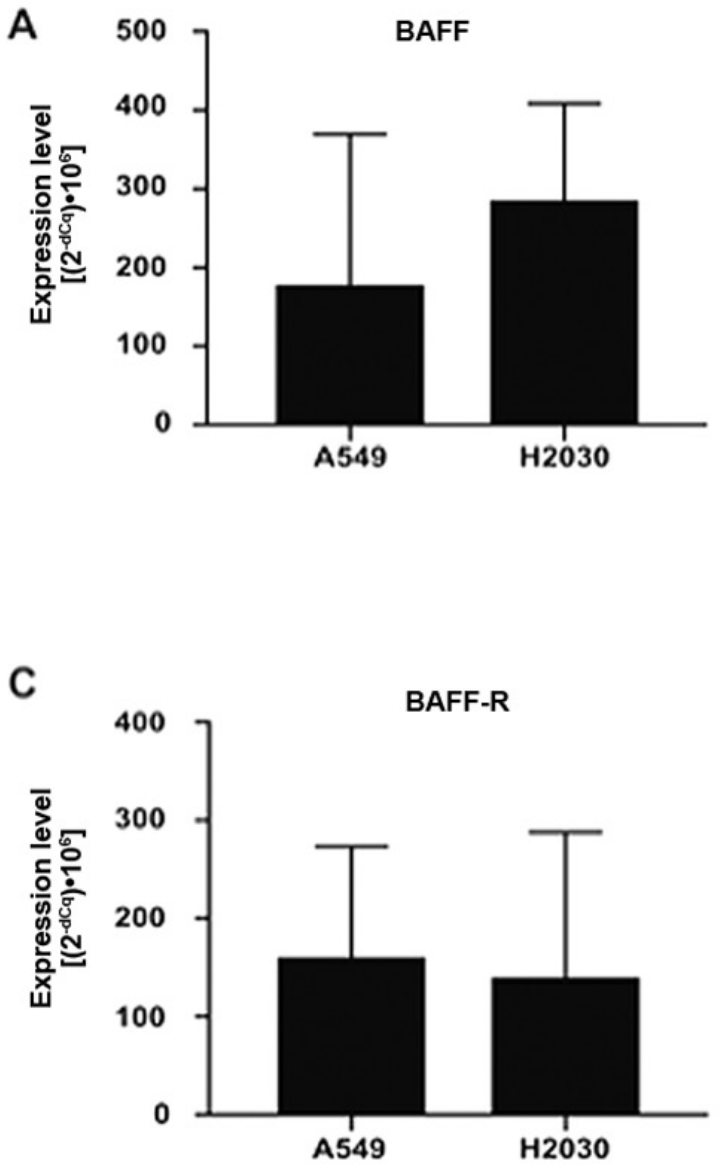

B

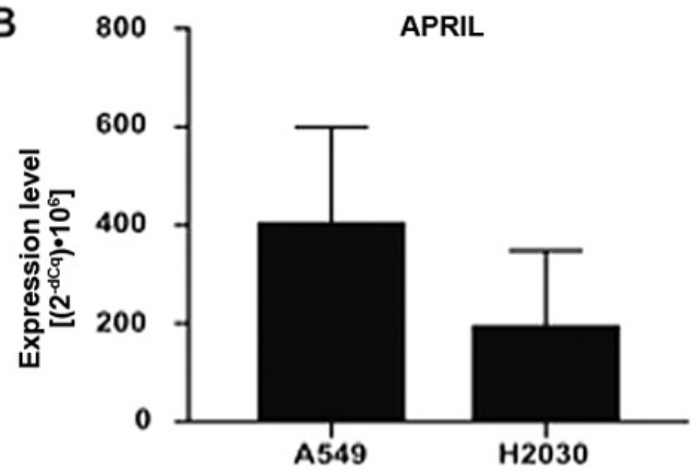

D

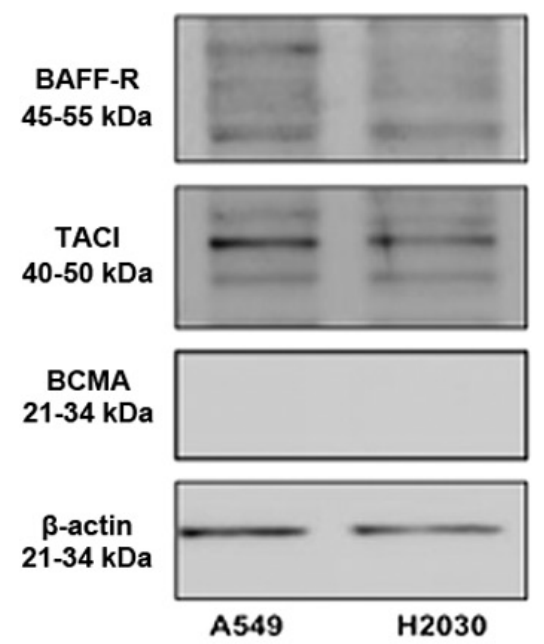

Figure 1. BAFF-R and TACI are expressed in non-small cell lung cancer cells. (A) BAFF, (B) APRIL and (C) BAFF-R gene expression levels in A549 and H2030 cell lines. (D) Representative western blottings for BAFF-R, TACI and BCMA in A549 and H2030 cell lines. No significant differences were observed. APRIL, a proliferation-inducing ligand; BAFF-R, B-cell activating factor receptor; TACI, transmembrane activator and CAML interactor; BCMA, B-cell maturation antigen.

of TACI and BCMA was detected in H2030 cells only, while in the A549 cell line, the expression of both receptors was under the detection limit (data not shown). Furthermore, no difference was found in the expression levels of BAFF, APRIL and BAFF-R among the analyzed cell lines (Fig. 1A-C). In addition, results from western blotting demonstrated that both cell lines expressed BAFF-R and TACI at the protein level, while no expression of BCMA was detected (Fig. 1D). These findings suggested that NSCLC cells could respond directly to BAFF and APRIL stimulation via BAFF-R and TACI signaling.

Effect of different BAFF and APRIL doses on NSCLC cells viability. Having found that both cell lines possess the potential to directly respond to BAFF and APRIL stimulation by the interaction with TACI and BAFF-R, we subsequently aimed to investigate the direct effects of both ligands on cancer cell viability. As expected, the results demonstrated that stimulation of $\mathrm{H} 2030$ and A549 cells with 50, 100 and $150 \mathrm{ng} / \mathrm{ml} \mathrm{BAFF} \mathrm{(Fig.} \mathrm{2A} \mathrm{and} \mathrm{B)} \mathrm{and}$ APRIL (Fig. 2C and D) did not affect NSCLC cell viability. These findings indicated that BAFF and APRIL were not toxic for NSCLC cells and could be used in further functional experiments.
NSCLC-derived BAFF and APRIL do not influence cell proliferation. Having found that both cell lines can produce the analyzed ligands, we aimed to investigate whether A549 and H2030 cell-derived BAFF and APRIL may directly influence their proliferation (Fig. 3). Functional experiments were performed with receptor blocking using functional-grade monoclonal antibodies. The results demonstrated that blocking TACI and BAFF-R separately or in combination did not influence the proliferation of A549 (Fig. 3C) and H2030 (Fig. 3D) cells. These results indicated that endogenous BAFF and APRIL may not increase tumor growth directly by increasing cancer cell proliferation.

Exogenous BAFF and APRIL did not influence NSCLC cell proliferation. Next, we wished to analyze whether exogenous BAFF and APRIL could directly affect NSCLC cell proliferation. Cells were stimulated with recombinant human BAFF and APRIL at 50, 100 and $150 \mathrm{ng} / \mathrm{ml}$. The results demonstrated no effect of exogenous stimulation with both ligands on A549 (Fig. 4A) and H2030 (Fig. 4B) cell proliferation, since no differences in the frequency of proliferating cells was observed (Fig. 4C-F). Furthermore, no effect on cancer cell invasiveness in response to BAFF and APRIL stimulation was observed compared with vehicle alone (Fig. 5). 

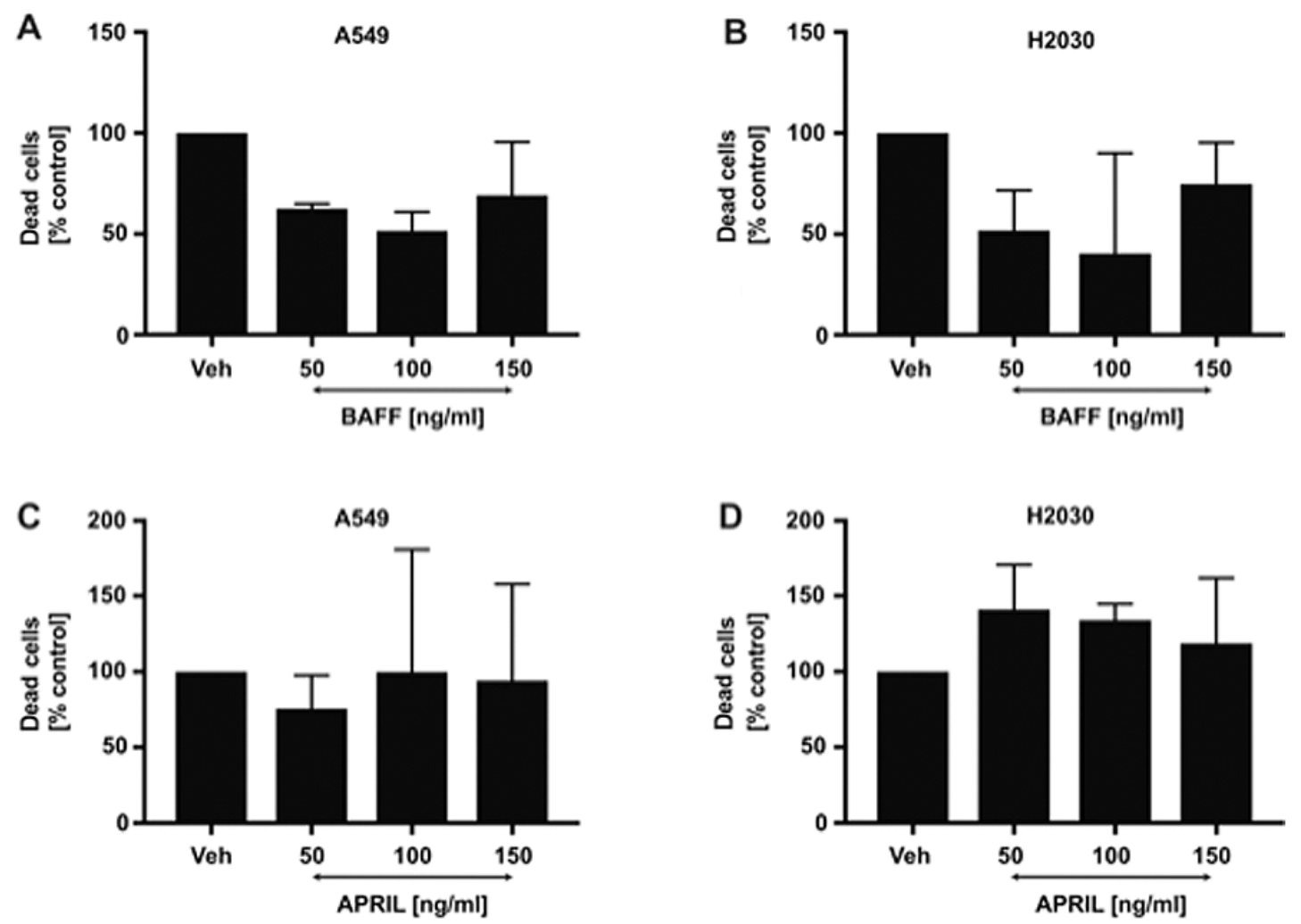

Figure 2. Effects of BAFF and APRIL signaling on non-small cell lung cancer cell viability. Effect of BAFF signaling on (A) A549 and (B) H2030 cell viability. Effects of APRIL signaling on (C) A549 and (D) H2030 cell viability. Cells were cultured in the presence of different concentrations of BAFF and APRIL or untreated (veh alone). No significant differences were observed. APRIL, a proliferation-inducing ligand; BAFF, B-cell activating factor; veh, vehicle.
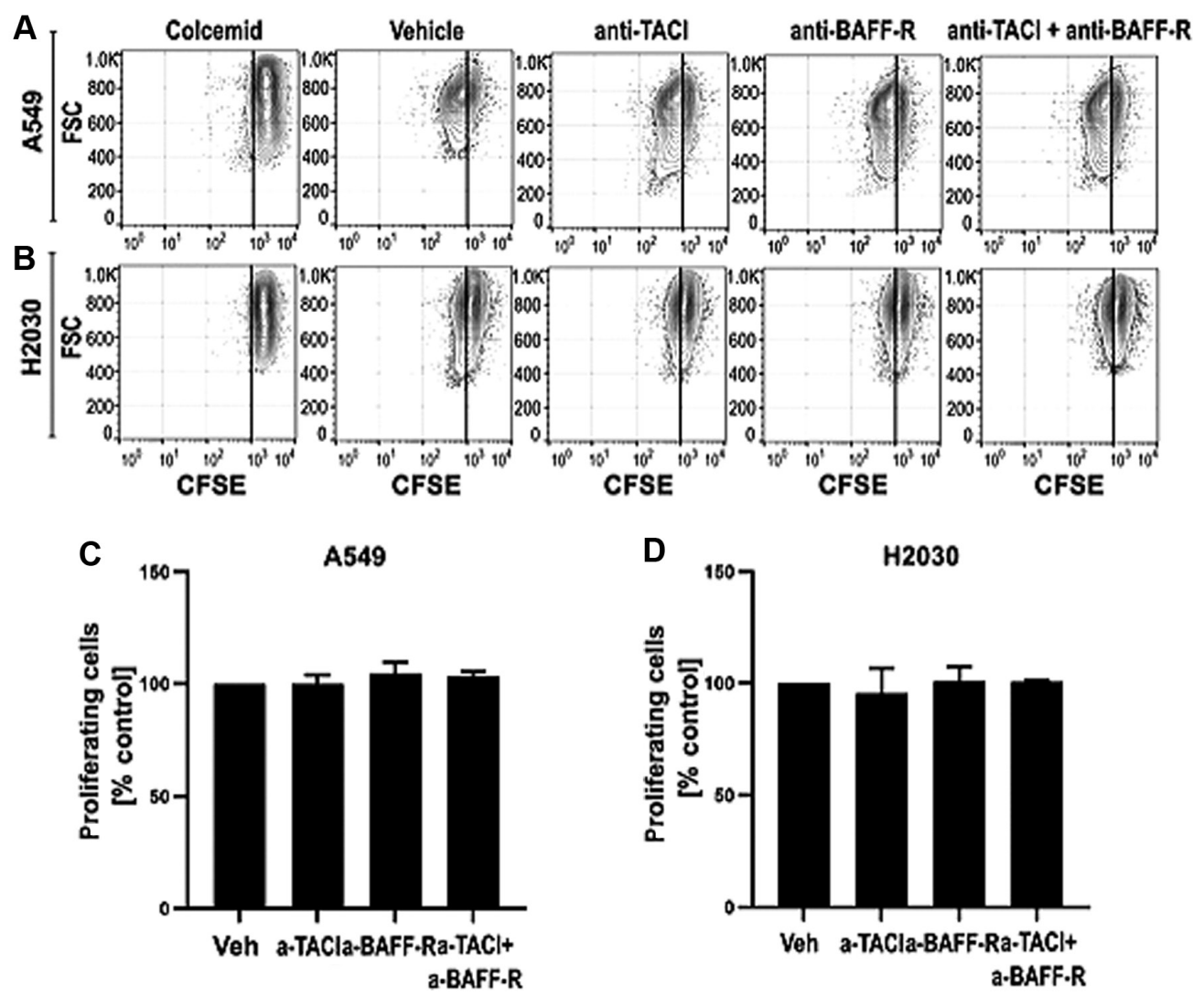

Figure 3. Endogenous BAFF and APRIL do not change non-small cell lung cancer cell proliferation. Representative flow cytometry density plots for CFSE based proliferation of (A) A549 and (B) H2030 cell lines with blocked TACI (anti-TACI) and/or BAFF-R (anti-BAFF-R). Effects of blocking TACI and/or BAFF-R in (C) A549 and (D) H2030 cell lines. Colcemid was used as a negative control of cancer cell proliferation (for gate set up). No significant differences were observed. BAFF-R, B-cell activating factor receptor; TACI, transmembrane activator and CAML interactor; vh, vehicle 

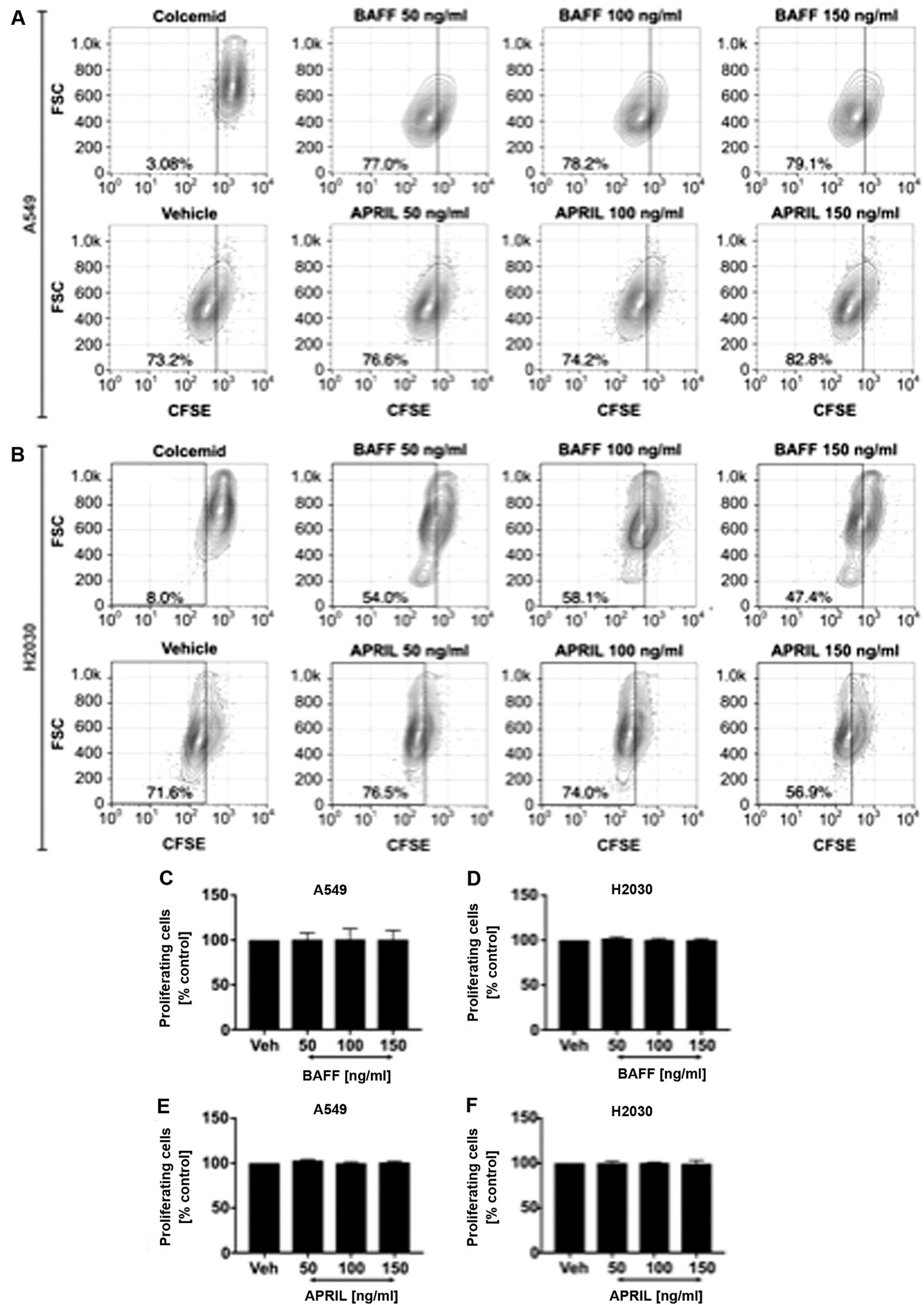

Figure 4. Direct effects of exogenous BAFF and APRIL signaling on non-small cell lung cancer cell proliferation. Representative flow cytometry density plots for CFSE based proliferation in BAFF and APRIL-treated (A) A549 and (B) H2030 cells. Effects of different concentrations BAFF and APRIL on A549 (C and E, respectively) and H2030 (D and F, respectively) cells. Colcemid was used as a negative control of cancer cell proliferation (for gate set up). No significant differences were observed. APRIL, a proliferation-inducing ligand; BAFF, B-cell activating factor; veh, vehicle. 


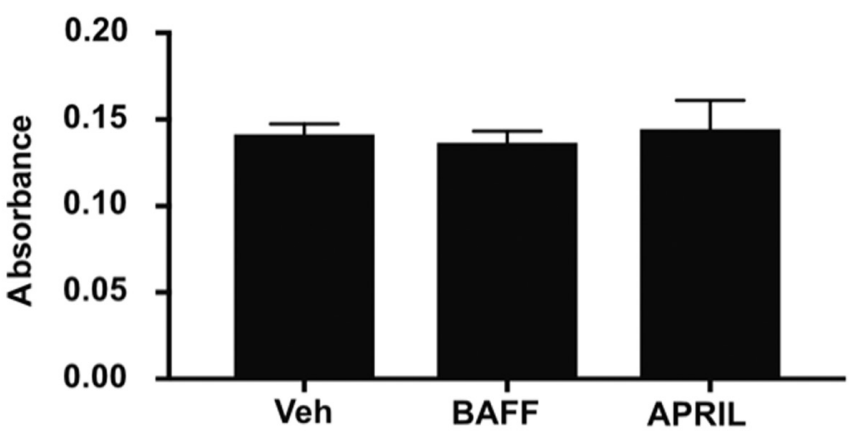

Figure 5. The influence of BAFF and APRIL signaling on non-small cell lung cancer cell aggressiveness. Effect of $150 \mathrm{ng} / \mathrm{ml}$ BAFF and APRIL treatments on A549 and H2030 cancer cell aggressiveness. 10\% FBS (vehicle) was used as a control. No significant differences were observed. APRIL, a proliferation-inducing ligand; BAFF, B-cell activating factor; veh, vehicle.

\section{Discussion}

The present study demonstrated that NSCLC cells possess the ability to respond directly to BAFF and APRIL stimulation via interaction with TACI and BAFF-R, while BCMA was undetectable at the protein level. Previous studies reported that BAFF and APRIL can enhance the proliferation of normal and malignant B cells $(11,20)$. In addition, previous studies from our group demonstrated that the expression of BCMA might serve as a prognostic factor for treatment response in patients with acute myeloid leukemia $(8,9)$. In solid tumors, BAFF and APRIL signaling is associated with cancer cell proliferation, such as in breast cancer (12), esophageal cancer (26), clear cell renal cell carcinoma (27), adult male germ cell tumor (28) and invasive bladder carcinoma (29). Furthermore, elevated local and systemic levels of BAFF and APRIL were shown to be associated with a higher stage and disease progression, such as in chronic graft versus host disease, systemic lupus erythormatosus and breast cancer tumor size $(12,13)$. Surprisingly, the present study demonstrated that BAFF and APRIL direct signaling did not serve an essential role in NSCLC aggressiveness, as no effect of BAFF and APRIL on NSCLC cell proliferation and invasiveness was reported. Conversely, previous studies reported that APRIL signaling in NSCLC cells promote tumor proliferation, migration and metastasis $(23,30)$. Consequently, both ligands may act as tumor supporters and pro-metastatic factors in an indirect manner. In fact, high BAFF and APRIL expression were shown in NSCLC tissues (22). It is therefore essential to determine whether BAFF and APRIL signaling in tumor-infiltrating or stromal cells, including tumor-infiltrating macrophages or tumor-associated fibroblasts, may play a role in tumor progression and spread.

Macrophages (alternatively activated) and fibroblasts are crucial components of tumor stroma. The progressive effects of macrophages and fibroblasts on tumor growth are associated with the release of growth factors and anti-inflammatory mediators, their promotion of cancer invasiveness by releasing matrix degradation enzymes, and their involvement in the recruitment of suppressive cells, including $\mathrm{T}$ regulatory cells to the tumor side $(31,32)$. Both aforementioned cell subsets have been shown to produce high levels of BAFF and APRIL; however, the effects of both ligands on the activation and biological function of tumor-infiltrating macrophages and tumor-associated fibroblasts remain elusive (18,24,33-35). $\mathrm{BAFF}$ via direct interaction with TACI may therefore induce monocyte maturation towards macrophages and, thus, contribute to tumor progression.

BAFF and APRIL signaling stimulate the expression of anti-apoptotic proteins, such as Bcl-2, Bcl-XL and Bcl-2-related protein A1 $(36,37)$. Both ligands may therefore serve as anti-apoptotic mediators and increase the survival of cancer cells subjected to chemotherapy (11). Interestingly, APRIL gene silencing was shown to increase the apoptotic susceptibility of gastric cancer cells (38). However, the present study demonstrated that BAFF and APRIL stimulation had no effects on the viability of NSCLC cells in normal conditions. Further investigation is therefore required to elucidate the impact of BAFF and APRIL on cancer cell susceptibility to cytotoxic therapy.

In summary, the results from the present study demonstrated that, despite the presence of TACI and BAFF-R in NSCLC cells, both BAFF and APRIL did not exert direct effects on cancer cell proliferation and invasiveness. Further studies are needed to elucidate the mechanisms of previously reported ex vivo associations between BAFF and APRIL and cancer progression $(12,13)$.

\section{Acknowledgements}

Not applicable.

\section{Funding}

This study was supported by the statutory founds of Medical University of Bialystok, Poland (grant no. N/ST/ZB/16/001/1113).

\section{Availability of data and materials}

The datasets used and/or analyzed during the current study are available from the corresponding author on reasonable request.

\section{Authors' contributions}

AE, MM and LB developed the research concept. AE and LB designed the experiments. MW, MT, DL and KG performed the experiments. MW, MT and JD performed statistical analysis and designed figures. MW and MT drafted the mancuscript. $\mathrm{AE}, \mathrm{LB}, \mathrm{JD}$ and $\mathrm{MM}$ revised the draft. AE, MM and BL confirmed the authenticity of all the raw data.All authors read and approved the final manuscript.

\section{Ethics approval and consent to participate}

Not applicable

\section{Patient consent for publication}

Not applicable

\section{Competing interests}

The authors declare that they have no competing interests. 


\section{References}

1. Molina JR, Yang P, Cassivi SD, Schild SE and Adjei AA: Non-small cell lung cancer: Epidemiology, risk factors, treatment, and survivorship. Mayo Clin Proc 83: 584-594, 2008.

2. Gajewski TF, Schreiber H and Fu YX: Innate and adaptive immune cells in the tumor microenvironment. Nat Immunol 14: 1014-1022, 2013.

3. Hirsch FR, Scagliotti GV, Mulshine JL, Kwon R, Curran WJ Jr, Wu YL and Paz-Ares L: Lung cancer: Current therapies and new targeted treatments. Lancet 389: 299-311, 2017.

4. Stankovic B, Bjørhovde HAK, Skarshaug R, Aamodt H, Frafjord A, Müller E, Hammarström C, Beraki K, Bækkevold ES Woldbæk PR, et al: Immune Cell Composition in Human Non-small Cell Lung Cancer. Front Immunol 9: 3101, 2019.

5. Liu X, Wu S, Yang Y, Zhao M, Zhu G and Hou Z: The prognostic landscape of tumor-infiltrating immune cell and immunomodulators in lung cancer. Biomed Pharmacother 95: 55-61, 2017.

6. Poh AR and Ernst M: Targeting macrophages in cancer: From bench to bedside. Front Oncol 8: 49, 2018.

7. Loyher PL, Hamon P, Laviron M, Meghraoui-Kheddar A, Goncalves E, Deng Z, Torstensson S, Bercovici N, Baudesson de Chanville C, Combadière B, et al: Macrophages of distinct origins contribute to tumor development in the lung. J Exp Med 215: 2536-2553, 2018.

8. Bolkun L, Grubczak K, Schneider G, Zembko P, Radzikowska U, Singh P, Kloczko J, Ratajczak MZ, Moniuszko M and Eljaszewicz A: Involvement of BAFF and APRIL in Resistance to Apoptosis of Acute Myeloid Leukemia. J Cancer 7: 1979-1983, 2016.

9. Bolkun L, Lemancewicz D, Jablonska E, Szumowska A, Bolkun-Skornicka U, Ratajczak-Wrona W, Dzieciol J and Kloczko J: The impact of TNF superfamily molecules on overall survival in acute myeloid leukaemia: Correlation with biological and clinical features. Ann Hematol 94: 35-43, 2015.

10. Meinl E, Thaler FS and Lichtenthaler SF: Shedding of BAFF/APRIL receptors controls B cells. Trends Immunol 39: 673-676, 2018.

11. Kern C, Cornuel JF, Billard C, Tang R, Rouillard D, Stenou V, Defrance T, Ajchenbaum-Cymbalista F, Simonin PY, Feldblum S, et al: Involvement of BAFF and APRIL in the resistance to apoptosis of B-CLL through an autocrine pathway. Blood 103 679-688, 2004.

12. Pelekanou V, Notas G, Athanasouli P, Alexakis K, Kiagiadaki F, Peroulis N, Kalyvianaki K, Kampouri E, Polioudaki H, Theodoropoulos P, et al: BCMA (TNFRSF17) induces APRIL and BAFF mediated breast cancer cell stemness. Front Oncol 8: $301,2018$.

13. Moreaux J, Veyrune JL, De Vos J and Klein B: APRIL is overexpressed in cancer: Link with tumor progression. BMC Cancer 9: 83, 2009.

14. Quinn J, Glassford J, Percy L, Munson P, Marafioti T, Rodriguez-Justo M and Yong K: APRIL promotes cell-cycle progression in primary multiple myeloma cells: Influence of D-type cyclin group and translocation status. Blood 117: 890-901, 2011.

15. Bolkun L, Lemancewicz D, Jablonska E, Kulczynska A, Bolkun-Skornicka U, Kloczko J and Dzieciol J: BAFF and APRIL as TNF superfamily molecules and angiogenesis parallel progression of human multiple myeloma. Ann Hematol 93: 635-644, 2014.

16. Yang S, Li JY and Xu W: Role of BAFF/BAFF-R axis in B-cell non-Hodgkin lymphoma. Crit Rev Oncol Hematol 91: 113-122, 2014.

17. Tai YT, Acharya C, An G, Moschetta M,Zhong MY,Feng X, Cea M, Cagnetta A, Wen K, van Eenennaam H, et al: APRIL and BCMA promote human multiple myeloma growth and immunosuppression in the bone marrow microenvironment. Blood 127:3225-3236, 2016.

18. Koizumi M, Hiasa Y, Kumagi T, Yamanishi H, Azemoto N, Kobata T, Matsuura B, Abe M and Onji M: Increased B cell-activating factor promotes tumor invasion and metastasis in human pancreatic cancer. PLoS One 8: e71367, 2013.

19. Kampa M, Notas G, Stathopoulos EN, Tsapis A and Castanas E: The TNFSF members APRIL and BAFF and their receptors TACI, BCMA, and BAFFR in oncology, with a special focus in breast cancer. Front Oncol 10: 827, 2020.
20. Novak AJ, Grote DM, Stenson M, Ziesmer SC, Witzig TE, Habermann TM, Harder B, Ristow KM, Bram RJ, Jelinek DF, et al: Expression of BLyS and its receptors in B-cell non-Hodgkin lymphoma: Correlation with disease activity and patient outcome. Blood 104: 2247-2253, 2004.

21. Notas G,Alexaki VI,KampaM,Pelekanou V,Charalampopoulos I, Sabour-Alaoui S, Pediaditakis I, Dessirier V, Gravanis A, Stathopoulos EN, et al: APRIL binding to BCMA activates a JNK2-FOXO3-GADD45 pathway and induces a G2/M cell growth arrest in liver cells. J Immunol 189: 4748-4758, 2012.

22. Dou H, Yan Z, Zhang M and Xu X: APRIL, BCMA and TACI proteins are abnormally expressed in non-small cell lung cancer. Oncol Lett 12: 3351-3355, 2016.

23. Dou H, Yan Z, Zhang M and Xu X: APRIL promotes non-small cell lung cancer growth and metastasis by targeting ERK1/2 signaling. Oncotarget 8: 109289-109300, 2017.

24. Qian Z, Qingshan C, Chun J, Huijun Z, Feng L, Qiang W, Qiang X and Min Z: High expression of TNFSF13 in tumor cells and fibroblasts is associated with poor prognosis in non-small cell lung cancer. Am J Clin Pathol 141: 226-233, 2014.

25. Livak KJ and Schmittgen TD: Analysis of relative gene expression data using real-time quantitative PCR and the 2(-Delta Delta C(T)) method. Methods 25: 402-408, 2001.

26. Hao Y, Triadafilopoulos G, Sahbaie P, Young HS, Omary MB and Lowe AW: Gene expression profiling reveals stromal genes expressed in common between Barrett's esophagus and adenocarcinoma. Gastroenterology 131: 925-933, 2006.

27. Lee C, Park JW, Suh JH and Moon KC: High expression of APRIL correlates with poor prognosis in clear cell renal cell carcinoma. Pathol Res Pract 211: 824-828, 2015.

28. Korkola JE, Houldsworth J, Chadalavada RS, Olshen AB, Dobrzynski D, Reuter VE, Bosl GJ and Chaganti RS: Down-regulation of stem cell genes, including those in a $200-\mathrm{kb}$ gene cluster at $12 \mathrm{p} 13.31$, is associated with in vivo differentiation of human male germ cell tumors. Cancer Res 66: 820-827, 2006.

29. Sanchez-Carbayo M, Socci ND, Lozano J, Saint F and Cordon-Cardo C: Defining molecular profiles of poor outcome in patients with invasive bladder cancer using oligonucleotide microarrays. J Clin Oncol 24: 778-789, 2006.

30. Sun B, Wang H, Wang X, Huang H, Ding W, Jing R, Shi G and Zhu L: A proliferation-inducing ligand: A new biomarker for non-small cell lung cancer. Exp Lung Res 35: 486-500, 2009.

31. Sahai E, Astsaturov I, Cukierman E, DeNardo DG, Egeblad M, Evans RM, Fearon D, Greten FR, Hingorani SR, Hunter T, et al: A framework for advancing our understanding of cancer-associated fibroblasts. Nat Rev Cancer 20: 174-186, 2020.

32. Chen $X$ and Song E: Turning foes to friends: Targeting cancer-associated fibroblasts. Nat Rev Drug Discov 18: 99-115, 2019.

33. Chen J, He D, Chen Q, Guo X, Yang L, Lin X, Li Y, Wu W, Yang Y, He J, et al: BAFF is involved in macrophage-induced bortezomib resistance in myeloma. Cell Death Dis 8: e3161, 2017.

34. Manfroi B, McKee T, Mayol JF, Tabruyn S, Moret S, Villiers C, Righini C, Dyer M, Callanan M, Schneider P, et al: CXCL-8/IL8 produced by diffuse large B-cell lymphomas recruits neutrophils expressing a proliferation-inducing ligand APRIL. Cancer Res 77: 1097-1107, 2017.

35. Lowin T, Anssar TM, Bäuml M, Classen T, Schneider M and Pongratz G: Positive and negative cooperativity of TNF and Interferon- $\gamma$ in regulating synovial fibroblast function and B cell survival in fibroblast/B cell co-cultures. Sci Rep 10: 780, 2020.

36. Mackay F and Tangye SG: The role of the BAFF/APRIL system in B cell homeostasis and lymphoid cancers. Curr Opin Pharmacol 4: 347-354, 2004.

37. He B, Chadburn A, Jou E, Schattner EJ, Knowles DM and Cerutti A: Lymphoma B cells evade apoptosis through the TNF family members BAFF/BLyS and APRIL. J Immunol 172: 3268-3279, 2004.

38. Ni SZ, Cao HY, Chen Z, Zhu Y and Xu ZK: siRNA interference with a proliferation-inducing ligand gene in the Sgr-7901 gastric carcinoma cell line. Asian Pac J Cancer Prev 13: 1511-1514, 2012. 